Published in final edited form as:

Am J Kidney Dis. 2016 December ; 68(6): 911-922. doi:10.1053/j.ajkd.2016.06.020.

\title{
Ultrafiltration Rate and Mortality in Maintenance Hemodialysis Patients
}

\author{
Magdalene M. Assimon, PharmD, MS ${ }^{1,2}$, Julia B. Wenger, $\mathbf{M P H}^{1}$, Lily Wang, $\mathrm{PhD}^{2,3}$, and \\ Jennifer E. Flythe, MD, MPH ${ }^{1,3}$ \\ ${ }^{1}$ University of North Carolina Kidney Center, Division of Nephrology and Hypertension, \\ Department of Medicine, UNC School of Medicine, Chapel Hill, NC \\ ${ }^{2}$ Department of Epidemiology, UNC Gillings School of Global Public Health, Chapel Hill, NC \\ ${ }^{3}$ Cecil G. Sheps Center for Health Services Research, University of North Carolina, Chapel Hill, \\ NC
}

\begin{abstract}
Background-Observational data have demonstrated an association between higher ultrafiltration (UF) rates and greater mortality among hemodialysis (HD) patients. Prior studies were small and did not consider potential differences in the association across body sizes and other related subgroups. No study has investigated UF rates normalized to anthropometric measures beyond body weight. Also, potential methodological shortcomings in prior studies have led to questions about the veracity of the UF rate-mortality association.
\end{abstract}

Study Design-Retrospective cohort.

Setting \& Participants-118,394 HD patients dialyzing in a large dialysis organization, 20082012.

Predictors-Mean 30-day UF rates were dichotomized at 13 and $10 \mathrm{~mL} / \mathrm{h} / \mathrm{kg}$, separately, and categorized using various cut-points. UF rates normalized to body weight, body mass index and body surface area were investigated.

Outcomes-All-cause mortality.

\footnotetext{
Corresponding Author: Jennifer E. Flythe MD, MPH, University of North Carolina Kidney Center, 7024 Burnett-Womack CB \#7155, Chapel Hill, NC 27599-7155, jflythe @ med.unc.edu, (tel) 919-445-2656, (fax) 919-966-4251.

Publisher's Disclaimer: This is a PDF file of an unedited manuscript that has been accepted for publication. As a service to our customers we are providing this early version of the manuscript. The manuscript will undergo copyediting, typesetting, and review of the resulting proof before it is published in its final citable form. Please note that during the production process errors may be discovered which could affect the content, and all legal disclaimers that apply to the journal pertain.

Financial Disclosure: Dr Flythe has received speaking honoraria from Dialysis Clinic Inc, Renal Ventures, American Renal Associates, American Society of Nephrology, and Baxter. Drs Flythe and Assimon have received research funding for research unrelated to this study from the Renal Research Institute, a subsidiary of Fresenius Medical Care, North America.

Contributions: Research idea and study design: MMA, JBW, JEF; data acquisition: MMA, JBW, LW, JEF; data analysis/interpretation: MMA, JBW, LW, JEF; statistical analysis: JBW, LW; supervision or mentorship: JEF. Each author contributed important intellectual content during manuscript drafting or revision and accepts accountability for the overall work by ensuring that questions pertaining to the accuracy or integrity of any portion of the work are appropriately investigated and resolved. JEF takes responsibility that this study has been reported honestly, accurately, and transparently; that no important aspects of the study have been omitted, and that any discrepancies from the study as planned have been explained.

Peer Review: Evaluated by 2 peer reviewers, a Statistical Editor, a Co-Editor, and the Editor-in-Chief.
} 
Measurements-Multivariable survival models were used to estimate the association between UF rate and all-cause mortality.

Results-At baseline, 21,735 (18.4\%) individuals had UF rates $>13 \mathrm{~mL} / \mathrm{h} / \mathrm{kg}$ and 48,529 $(41.0 \%)$ had UF rates $>10 \mathrm{~mL} / \mathrm{h} / \mathrm{kg}$. Median follow-up time was 2.3 years, and the mortality rate was 15.3 deaths per 100 patient-years. Compared to UF rates $\unlhd 3$, UF rates $>13 \mathrm{~mL} / \mathrm{h} / \mathrm{kg}$ were associated with greater mortality (adjusted HR, 1.31; 95\% CI, 1.28-1.34). Compared to UF rates $\leq 10$, UF rates $>10 \mathrm{~mL} / \mathrm{h} / \mathrm{kg}$ were associated with greater mortality (adjusted HR, 1.22; 95\% CI, 1.20-1.24). Findings were consistent across subgroups of sex, race, dialysis vintage, session duration, and body size. Higher UF rates were associated with greater mortality when normalized to body weight, body mass index, and body surface area.

Limitations-Residual confounding cannot be excluded given the observational study design.

Conclusions-Regardless of the threshold implemented, higher UF rate was associated with greater mortality in the overall study population and across key subgroups. Randomized controlled trials are needed to investigate whether UF rate reduction improves clinical outcomes.

Index words-hemodialysis, mortality, ultrafiltration rate (UFR), body size, body weight, body mass index (BMI), body surface area (BSA), anthropometric measures, metabolic mass, rapid fluid removal, end-stage renal disease (ESRD)

Hemodialysis (HD) patients have high rates of morbidity and mortality. ${ }^{1}$ Fluid removal practices likely contribute to these poor outcomes. Existing data support an association between more rapid fluid removal during dialysis and greater mortality. ${ }^{2-4}$ End-organ ischemia of the heart, brain and gut from overt and subclinical hemodynamic instability plausibly underlie this association. ${ }^{5-8}$ Ultrafiltration (UF) rate is quantifiable and represents a modifiable fluid-related aspect of the HD prescription that is potentially within dialysis facility control. Currently, the Centers for Medicare \& Medicaid Services (CMS) is considering an UF rate threshold of $13 \mathrm{~mL} / \mathrm{h} / \mathrm{kg}$ as a quality measure to assess dialysis facility fluid management, and such a threshold has been incorporated into the CMS 2016 End Stage Renal Disease Core Survey. 9,10

Three observational investigations have demonstrated harm from greater UF rates. ${ }^{2-4}$ However, the studies are modestly sized, precluding robust analyses among key subgroups with plausibly different UF rate-outcome associations. The UF rate threshold delineating heightened risk may vary by patient type, which, if true, would make a single UF rate benchmark inappropriate as a quality measure. Patient characteristics such as body size and composition influence total body water distribution and plasma refill, making body size and its correlating factors of race and sex plausible modifiers of the UF rate-outcome association. Additionally, UF rates are typically normalized to body weight. However, UF rate normalization to other anthropometric measures that may capture metabolic mass better has not been evaluated. Finally, potential shortcomings in prior analyses may have biased risk estimates. Investigators included interdialytic weight gain (IDWG), session duration, and weight, all UF rate calculation components, in multivariable models. Such inclusion may obscure the true association between UF rates and outcomes. ${ }^{11}$ The aforementioned uncertainties, along with the observational nature of the data, have led to reluctance by guideline bodies such as NKF-KDOQI (National Kidney Foundation-Kidney Disease 
Outcomes Quality Initiative) to issue firm UF rate guidelines and questions about the appropriateness of a single, weight-based UF rate threshold for all patients. ${ }^{12,13}$

We undertook this study to further investigate the association of UF rate and mortality in a large, prevalent HD patient cohort. We examined the UF rate-mortality association across body size, sex, race, dialysis vintage, and HD session duration subgroups. We also investigated the robustness of the UF rate-mortality association across UF rate calculations normalized to different anthropometric measures.

\section{METHODS}

\section{Study Design}

Data were obtained from a cohort of 337,863 patients receiving HD at a single large dialysis organization (LDO) from June 2008 through December 2012. Figure 1 displays study design. Patients were included if they were age 18 years or older, received in-center HD, and had been on dialysis for $\geq 90$ days at study entry. Exclusion criteria included the occurrence of death or censoring event during the exposure period, $<7$ in-center HD treatments during the exposure period, and missing UF rate data. We identified all in-center HD patients who met study eligibility criteria as of June 1, 2008 (study start date). For patients entering the LDO database later in calendar time, eligibility criteria was assessed on the first outpatient HD treatment date in the data. This date was the study entry date for patients entering the cohort after June 1, 2008.

Demographic characteristics (age, sex, race, height, and dialysis vintage) and comorbid conditions (diabetes, heart failure, coronary disease) were considered as of cohort entry. Laboratory and HD treatment data were captured in a 30-day baseline period. Laboratory covariates (urea reduction ratio [URR], albumin, sodium, creatinine, hemoglobin, and phosphate) were considered as the last non-missing values in the baseline period. Predialysis systolic blood pressure (SBP) was considered as the mean of values in the baseline period. Ultrafiltration rates were assessed in a 30-day exposure period following the baseline period. Patients surviving the baseline and exposure periods (to study day 60) were followed forward in historical time to death, censoring event, or study end (December 31, 2013).

This study was approved by the University of North Carolina at Chapel Hill Institutional Review Board (IRB number 15-2100). Given the large cohort size, data anonymity, and nonintrusive research, informed consent requirements were exempted.

\section{Data Collection}

All data were obtained from the LDO's medical record. Demographics were recorded upon admission to an organization facility. Comorbid conditions were determined by a nephrologist at the time of patient entry to the LDO and updated based upon clinical course. Laboratory results were measured biweekly or monthly. Dialysis treatment data including session duration and pre- and post-dialysis weights were recorded on a treatment-totreatment basis. Interdialytic weight gain was defined as pre-dialysis weight $(\mathrm{kg})$ minus post-dialysis weight $(\mathrm{kg})$ from the previous treatment. Based on review of relevant medical records and per standardized LDO protocol, death dates were recorded by facility personnel. 


\section{Designation of Exposures and Outcome}

In primary analyses, prescribed UF rate normalized to body weight $(\mathrm{mL} / \mathrm{h} / \mathrm{kg})$ was calculated as follows: IDWG (kg)/prescribed session duration (h)/post-HD weight $(\mathrm{kg})$ for each exposure period HD treatment. Prescribed UF rate was assumed constant during each treatment and was considered as a mean of UF rate values over the 30-day exposure period. A 30-day exposure period was selected a priori to limit survivorship bias and to mirror prior analyses. ${ }^{3,4}$ Sixty and 90-day periods were considered in sensitivity analyses, and results were analogous (Table S1, available as online supplementary material). Additional sensitivity analyses considered time-updated UF rate and mortality.

In primary analyses, prescribed UF rate was treated as binary ( $₫ 0$ versus $>10 \mathrm{~mL} / \mathrm{h} / \mathrm{kg}$ and $\leq 3$ versus $>13 \mathrm{~mL} / \mathrm{h} / \mathrm{kg}$, separately) to mirror the dichotomized approach of quality measures. ${ }^{14}$ Secondary analyses considered categorized UF rates $(<10,10-13$, and $>13$ $\mathrm{mL} / \mathrm{h} / \mathrm{kg})$ consistent with prior studies ${ }^{2,4}$ and more granular UF rate categories $(<6,6-<8,8$ $<10,10-<12,12-<14$, and $\geq 14 \mathrm{~mL} / \mathrm{h} / \mathrm{kg}$ ). To evaluate for a dose-response relationship, we constructed a frequency-based UF rate exposure definition. We considered the proportion of HD treatments in the exposure period with UF rates $>13 \mathrm{~mL} / \mathrm{h} / \mathrm{kg}:<25 \%, 25-50 \%$, and $>50 \%$ of treatments. We selected a threshold of $13 \mathrm{~mL} / \mathrm{h} / \mathrm{kg}$ to mirror the CMS surveyor tool cut-point. ${ }^{10}$ We conducted additional analyses considering delivered UF rates. Delivered UF rate indexed to body weight $(\mathrm{mL} / \mathrm{h} / \mathrm{kg})$ was calculated as: UF volume $(\mathrm{mL}) /$ delivered session duration (h)/post-HD weight $(\mathrm{kg})$.

Secondary analyses were performed considering UF rate normalized to body mass index (BMI, $\mathrm{kg} / \mathrm{m}^{2}$ ) and body surface area $\left(\mathrm{BSA}, \mathrm{m}^{2}\right.$ ), separately. To mirror primary analyses, BMI and BSA were calculated based on post-HD weight. The BSA was calculated according to Du Bois. ${ }^{15}$ In these analyses, UF rate to BMI $\left(\mathrm{mL} / \mathrm{h} / \mathrm{kg} / \mathrm{m}^{2}\right)$ and UF rate to BSA $\left(\mathrm{mL} / \mathrm{h} / \mathrm{m}^{2}\right)$ were dichotomized at the $80^{\text {th }}$ percentiles. The $80^{\text {th }}$ percentile threshold was selected to mirror the primary analysis, as $13 \mathrm{~mL} / \mathrm{h} / \mathrm{kg}$ represented the $80^{\text {th }}$ percentile of UF rate normalized to body weight.

The outcome of interest was all-cause mortality. Patients were considered at-risk for the study outcome following the exposure period and remained at-risk until death or censoring for loss to follow-up or study end (December 31, 2013). Dialysis modality change and kidney transplantation were treated as competing risks. ${ }^{16}$

\section{Statistical Analyses}

Analyses were performed using SAS version 9.4 (SAS Institute Inc, Cary, NC). Baseline patient characteristics were described across UF rate groups as counts and proportions for categorical variables and as means \pm standard deviations for continuous variables.

Time-to-event analyses were conducted using unadjusted and adjusted Fine and Gray proportional subdistribution hazards regression models to estimate hazard ratios (HRs). The proportionality assumption was confirmed via Schoenfeld residual testing. Missing values of laboratory variables were imputed using the Markov chain Monte Carlo method with 10 imputations (albumin, $n=2,184$; creatinine, $n=7,473$; phosphorus, $n=1,430$; hemoglobin, $\mathrm{n}=627$; and URR, $\mathrm{n}=1,642) .{ }^{17}$ Implausible values of pre- and post-HD weight, session 
duration, and post-HD weight were considered missing. Collinearity of exposure and model covariates was evaluated by the variance inflation factor. Interdialytic weight gain, session duration, and post-HD weight demonstrated moderate collinearity with UF rate and were excluded from the model (variance inflation factor $\geq 1.3$ versus $=1.0$ for all other model variables).

Effect modification of the UF rate-mortality association on the basis of sex, race (black versus non-black), ethnicity (Hispanic versus non-Hispanic), body weight $\left(<20^{\text {th }}\right.$ versus $>80^{\text {th }}$ percentile of post-HD weight), dialysis vintage ( $<4$ versus $\geq 4$ years), and session duration ( $<4$ versus $\geq 4 \mathrm{~h}$ ) was explored through restriction subgroup analyses. Significance of interaction was assessed by the Wald test of nested models that did and did not include two-way cross product terms. Restricted analyses, using the same analytic methods as primary analyses, were performed in subgroups of interest (session duration $\geq 4 \mathrm{~h}$ and dialysis vintage $\geq 4$ years). In secondary analyses the Vuong test was used to compare the relative mortality predictive value of UF rates normalized to body weight, $\mathrm{mL} / \mathrm{h} / \mathrm{kg}$, (versus $\mathrm{BMI}, \mathrm{mL} / \mathrm{h} / \mathrm{kg} / \mathrm{m}^{2}$, and BSA, $\mathrm{mL} / \mathrm{h} / \mathrm{m}^{2}$, separately) based on the cumulative incidence function of fully adjusted models. ${ }^{18}$

In sensitivity analyses, we assessed the association between time-updated UF rate $(\mathrm{mL} / \mathrm{h} / \mathrm{kg})$ and mortality using marginal structural proportional hazards models. Marginal structural models estimate the effect of a time-varying exposure on an outcome by controlling for the effects of time-dependent confounders. ${ }^{19,20}$ Table $a$ and figure $a$ of Item S1 provide detailed methods.

\section{RESULTS}

\section{Cohort Characteristics}

Figure 2 displays a flowchart of patient selection. Table 1 displays cohort characteristics across prescribed UF rate groups. Compared with patients with UF rates $\leq 3 \mathrm{~mL} / \mathrm{h} / \mathrm{kg}$, patients with UF rates $>13 \mathrm{~mL} / \mathrm{h} / \mathrm{kg}$ had smaller body sizes, were younger, and were more likely to be female, non-black, Hispanic, and have comorbid heart failure, longer dialysis vintage, shorter session durations, and larger IDWGs. Table S2 displays comparisons of included and excluded patients.

Overall, 118,394 patients underwent 1,511,740 treatments during the exposure period. Of these, $69,865(59.0 \%)$ patients had UF rates $<10 \mathrm{~mL} / \mathrm{h} / \mathrm{kg}, 26,794(22.6 \%)$ had UF rates 10$13 \mathrm{~mL} / \mathrm{h} / \mathrm{kg}$, and 21,735 (18.4\%) had UF rates $>13 \mathrm{~mL} / \mathrm{h} / \mathrm{kg}$. The median followup time was 2.3 (interquartile range [IQR], 1.0-4.4) years, and there were 310,064 patient-years of total follow-up time. Mortality occurred at a rate of 15.3 deaths per 100 patient-years.

\section{Primary Analyses}

Unadjusted and adjusted associations between prescribed UF rate indexed to body weight and mortality are presented in Table 2 . Prescribed UF rates $>13$ (versus $\unlhd 3$ ) $\mathrm{mL} / \mathrm{h} / \mathrm{kg}$ were associated with greater mortality (adjusted HR, 1.31; 95\% CI, 1.28-1.34). At a lower threshold, prescribed UF rates $>10$ (versus $\leq 10$ ) $\mathrm{mL} / \mathrm{h} / \mathrm{kg}$ were also associated with greater mortality (adjusted HR, 1.22; 95\% CI, 1.20-1.24). As we lacked data on residual urine 
output, we performed analyses restricted to patients with dialysis vintages $\geq 4$ years $(n=$ 40,706). Results were analogous to those of the full cohort (Table 2). We observed a doseresponse association between UF rate and mortality, with more frequent exposure to elevated UF rates associated with increased harm. Compared with $<25 \%$ of treatments above the threshold, incrementally greater proportions of treatments with UF rates $>13 \mathrm{~mL} / \mathrm{h} / \mathrm{kg}$ were associated with incrementally greater mortality (adjusted HRs of 1.26 [95\% CI, 1.23-1.29] for $25 \%-49 \%$ of treatments and 1.40 [95\% CI, 1.36-1.43] for $250 \%$ of treatments).

\section{Sensitivity Analyses Related to Exposure Specification}

In secondary analyses considering more finely categorized UF rates, mortality risk increased incrementally across successively greater UF rate categories (Table 3 ). When UF rate was considered continuously, mortality risk rose by $3 \%$ for every $1 \mathrm{~mL} / \mathrm{h} / \mathrm{kg}$ UF rate increase.

Delivered and prescribed UF rates were highly correlated ( $\mathrm{r}=0.96 ; \mathrm{p}<0.005)$. Results from analyses considering the delivered UF rate-mortality association were analogous to primary prescribed UF rate results (Table S3). To investigate the association of UF rates and mortality without influence from risk incurred during the long interdialytic interval, we performed analyses excluding HD treatments following the 72 hour interdialytic interval. Results were consistent with full cohort findings (Table S4). Results from models investigating time-updated prescribed UF rate and mortality were also analogous to primary findings (Item S1).

\section{Subgroup Analyses}

Table 4 displays results from subgroup analyses. Higher prescribed UF rate (across all specifications) was associated with significantly greater mortality in all subgroups studied. When UF rate was dichotomized at $13 \mathrm{~mL} / \mathrm{h} / \mathrm{kg}$, this association was more pronounced in blacks versus non-blacks, non-Hispanics versus Hispanics, patients with dialysis vintage $\geq 4$ years versus $<4$ years, patients with session durations $\geq 4$ hours versus $<4$ hours, and heavier versus lighter patients ( $\mathrm{p}$ for interaction $<0.05$ for all, indicating that subgroup effect size differences were significant). Similarly, prescribed UF rate considered continuously (per 1 $\mathrm{mL} / \mathrm{h} / \mathrm{kg}$ ) was associated with greater mortality across all subgroups. Effect sizes were significantly greater among females versus males, non-Hispanics versus Hispanics, patients with dialysis vintage $<4$ years versus $\geq 4$ years, and heavier versus lighter patients ( $\mathrm{p}$ for interaction $<0.05$ for all).

\section{Body Size Influence}

When prescribed UF rate was normalized to BMI, UF rates $>37$ (versus $\leq 37$ [the $80^{\text {th }}$ percentile]) $\mathrm{mL} / \mathrm{h} / \mathrm{kg} / \mathrm{m}^{2}$ were associated with increased mortality (adjusted HR, 1.27; 95\% CI, 1.24-1.30). When normalized to BSA, UF rates $>500$ (versus 500 [the $80^{\text {th }}$ percentile]) $\mathrm{mL} / \mathrm{h} / \mathrm{m}^{2}$ were associated with increased mortality (adjusted HR, 1.23; 95\% CI, 1.20-1.26). Using the Vuong test, modeling UF rate normalized to weight (compared to BMI and BSA, separately) was most predictive of mortality ( $\mathrm{p}<0.001$ for both). ${ }^{18}$

To further explore the UF rate-mortality association across body sizes, we categorized body size as $<20^{\text {th }}, 20^{\text {th }}-80^{\text {th }}$, and $>80^{\text {th }}$ percentile of post-HD body weight, BMI and BSA 
(separately). Again, UF rates $>13$ (versus $\leq 3$ ) $\mathrm{mL} / \mathrm{h} / \mathrm{kg}$ were associated with greater death risk in each subgroup. The association was strongest among patients with higher versus lower body weight and at higher versus lower BMI. The magnitude of association was similar across BSA strata (Figure 3).

\section{Ultrafiltration Rate Quality Measure Considerations}

As the proposed CMS Quality Incentive Program (QIP) UF rate measure excludes patients with prescribed session durations $\geq 4 \mathrm{~h}$ from the metric numerator, we performed analyses restricted to patients with prescribed session durations $\geq 4 \mathrm{~h}(\mathrm{n}=39,890)$. Among patients with session durations $\geq 4 \mathrm{~h}$, prescribed UF rates $>13$ (versus $\unlhd 3$ ) $\mathrm{mL} / \mathrm{h} / \mathrm{kg}$ and prescribed UF rates $>10$ (versus $\mathrm{s} 0$ ) $\mathrm{mL} / \mathrm{h} / \mathrm{kg}$ were associated with greater mortality, regardless of body size. These associations were more pronounced in heavier patients $\left(>80^{\text {th }}\right.$ percentile of body weight) versus lighter patients (Table 5).

\section{DISCUSSION}

Prior studies have shown associations between rapid fluid removal and mortality among HD patients, but questions about study design and potential differences across subpopulations remain. In the largest to-date observational cohort, we demonstrated an association between greater UF rate and mortality, showing incrementally greater harm from UF rates starting at $6 \mathrm{~mL} / \mathrm{h} / \mathrm{kg}$. Our results suggest that notable UF-related harm begins before $10 \mathrm{~mL} / \mathrm{h} / \mathrm{kg}$, substantially lower than the proposed quality measure threshold of $13 \mathrm{~mL} / \mathrm{h} / \mathrm{kg}$. The UF rate-mortality association was significant across all body sizes, with larger patients having greater mortality risk from higher UF rates. Ultrafiltration rate normalized to body weight had a stronger association with mortality (versus normalization to BMI or BSA). Findings were robust across key sub-populations.

To date, three observational studies have examined the UF rate-mortality association. There have been no randomized-controlled trials. In a DOPPS (Dialysis Outcomes Practice Patterns Study) analysis, Saran et al. demonstrated a modest association between UF rates $>10 \mathrm{~mL} / \mathrm{h} / \mathrm{kg}$ and all-cause mortality. ${ }^{2}$ In an Italian cohort, Movilli et al. identified a UF rate threshold of $12.2 \mathrm{~mL} / \mathrm{h} / \mathrm{kg}$ as the most predictive cut-point of mortality. ${ }^{3}$ In a post-hoc analysis of the Hemodialysis (HEMO) Study, Flythe et al. found that UF rates $>13 \mathrm{~mL} / \mathrm{h} / \mathrm{kg}$ (versus $<10 \mathrm{~mL} / \mathrm{h} / \mathrm{kg}$ ) were associated with greater mortality. ${ }^{4}$ Effect modification on the basis of heart failure was observed, suggesting that risk may occur at rates of $10 \mathrm{~mL} / \mathrm{h} / \mathrm{kg}$ in some populations. In fact, spline analyses showed that the UF rate risk began to rise at 10 $\mathrm{mL} / \mathrm{h} / \mathrm{kg}$ among all patients. ${ }^{4}$ Mechanistic studies evaluating intradialytic echocardiography, troponin and endotoxin have established hemodynamic-induced end-organ ischemia as a potential mediator of the UF rate-mortality association. $5,6,8,21$

Despite consistent findings across existing epidemiologic studies, the methodological shortcomings of these investigations have tempered enthusiasm for UF rate clinical guidelines. ${ }^{22-24}$ We sought to address these uncertainties. The IDWG (or UF volume), session duration, and post-HD weight all contribute to the UF rate calculation and were included in prior multivariable models, potentially introducing effect size inaccuracies. In our new analyses, we did not adjust for these factors as controlling for these variables 
obscures interpretation of findings. Stated otherwise, accepting that high UF rate must result from high IDWG, low session duration, low body weight, or some combination thereof, we did not artificially constrain these factors analytically but accepted their inherent contributions to UF rate. Additionally, concern for confounding from residual kidney function has led to scrutiny of prior studies as urine output is a critical confounder. ${ }^{23}$ To address this, we performed analyses restricted to patients on dialysis for $\geq 4$ years, a population with generally low urine output.

Our present analyses demonstrate that prescribed (and delivered) UF rates $>10 \mathrm{~mL} / \mathrm{h} / \mathrm{kg}$ are associated with greater mortality. This finding is consistent with Saran et al. and the Flythe et al. spline analysis showing a steep rise in UF rate-related mortality risk at $10 \mathrm{~mL} / \mathrm{h} / \mathrm{kg}$. ${ }^{2,4}$ An UF rate threshold of $13 \mathrm{~mL} / \mathrm{h} / \mathrm{kg}$, as instituted in the Core Survey and as proposed for the 2019 CMS QIP, is likely conservative. ${ }^{9,10}$ Additionally, the National Quality Forumendorsed UF rate measure includes a session length restriction. The metric numerator includes only patients with UF rates $>13 \mathrm{~mL} / \mathrm{h} / \mathrm{kg}$ and delivered session durations $<4$ hours. While this restriction may be in-line with patient preference data showing aversion to longer session lengths, ${ }^{25}$ our data demonstrate that patients with longer session durations incur greater mortality risk at higher UF rates. We also observed a dose-response association between UF rate and mortality: more frequent exposure to higher UF rates is associated with an incrementally higher death risk. Frequency-based definitions of UF rates may better capture risk than single treatment or mean-based UF rate definitions. Reassuringly, we observed the UF rate-mortality association to be robust across subgroups, rendering a single mean-based threshold approach reasonable. We also observed similar associations between prescribed and delivered UF rates and mortality, providing reassurance regarding the proposed quality measure's capture of delivered UF rates. Together, these data provide strong observational evidence supporting an association between greater UF rates and mortality.

Fluid removal-related harm occurs when the UF rate exceeds the plasma refill rate and subclinical or clinical hemodynamic compromise occurs. Vascular refill is influenced by many factors including body size, sex, nutritional status, total body volume status and distribution, and blood flow distribution. ${ }^{26}$ It is plausible that the UF rate-outcome association varies across body types. Therefore, we considered fluid removal normalized to body weight, BMI and BSA. Ultrafiltration rate normalized to weight had the strongest association with mortality, but, when UF rate was modeled continuously, the effect size varied across sex and body size with females (versus males) and heavier (versus lighter) patients having greater mortality risk. Similar effect size differences were observed when UF rate was normalized to BMI. Normalizing UF rate to BSA produced more stable effect estimates across BSA strata. The ideal indexing method might yield similar strengths of association across body sizes as observed with BSA. However, the effect size differences across body sizes when UF rate was normalized to both weight and BMI were modest, and all three normalization methods revealed significantly greater mortality with higher UF rates across all body sizes. As body weight is readily available for UF rate calculation in the clinic and effect sizes only modestly different across body size strata, UF rate normalization to body weight is reasonable. 
Several limitations of our study should be acknowledged. This is an observational analysis and may contain uncontrolled confounding. To minimize confounding from difficult-tomeasure factors such as health status, we controlled for variables including albumin, phosphate, creatinine, albumin, and weight. Related, we performed analyses restricted to patients of advanced dialysis vintage to minimize confounding from residual urine output. Nevertheless, we cannot rule out the possibility of confounding from these factors or other unconsidered factors. For example, body size, clearance, and session duration are closely related. Despite including URR and body size (via UF rate) in our models, we cannot ruleout residual confounding from clearance and body size-related factors. We also lacked data on dialysate and dietary sodium, potential confounders of the UF rate-mortality association. Reassuringly, the addition of serum sodium to multivariable models did not substantially alter UF rate-mortality effect estimates (Table S5), but residual confounding from these and other factors cannot be excluded. Prospective study of UF rate and outcomes is warranted. Second, we were unable to investigate cause-specific mortality due to lack of adjudicated death causes in our database. Third, we were unable to consider intradialytic symptoms due to lack of symptom data. Fourth, our data were derived from a single LDO and may not be representative of other dialysis providers. Finally, our study included adult, in-center maintenance HD patients with dialytic vintage $\geq 90$ days. Results should not be extrapolated to excluded populations such as incident HD patients.

In conclusion, we demonstrated an association between UF rates $>10 \mathrm{~mL} / \mathrm{h} / \mathrm{kg}$ (versus $\leq 10$ ) and all-cause mortality and showed an incremental rise in UF-related risk beginning at a UF rate of $6 \mathrm{~mL} / \mathrm{h} / \mathrm{kg}$. Additionally, we found the UF rate-outcome association to be robust across body size, sex, and racial subgroups and provided evidence supporting normalization of UF rate to weight versus other anthropometric metrics. The richness of the UF rateoutcome observational evidence base and the regulatory interest in adoption of an UF rate quality measure calls for a randomized controlled trial investigation of UF rates and outcomes.

\section{Supplementary Material}

Refer to Web version on PubMed Central for supplementary material.

\section{Acknowledgments}

The authors thank DaVita Clinical Research for providing data for this study. DaVita Clinical Research had no role in the design or implementation of this study or the decision to publish. The authors thank Alan Brookhart for data access and his insightful comments on analyses and Diane Reams for her data and contract management assistance.

Support: Dr Assimon is supported by National Institute of Diabetes and Digestive and Kidney Diseases training grant T32 DK007750.

\section{References}

1. Collins AJ, Foley RN, Chavers B, et al. US Renal Data System 2013 annual data report. Am J Kidney Dis. 2014; 63(1 (suppl 1)):e1-e420.

2. Saran R, Bragg-Gresham JL, Levin NW, et al. Longer treatment time and slower ultrafiltration in hemodialysis: associations with reduced mortality in the DOPPS. Kidney Int. 2006; 69(7):12221228. [PubMed: 16609686] 
3. Movilli E, Gaggia P, Zubani R, et al. Association between high ultrafiltration rates and mortality in uraemic patients on regular haemodialysis. A 5-year prospective observational multicentre study. Nephrol Dial Transplant. 2007; 22(12):3547-3552. [PubMed: 17890254]

4. Flythe JE, Kimmel SE, Brunelli SM. Rapid fluid removal during dialysis is associated with cardiovascular morbidity and mortality. Kidney Int. 2011; 79(2):250-257. [PubMed: 20927040]

5. Burton JO, Jefferies HJ, Selby NM, McIntyre CW. Hemodialysis-induced cardiac injury: determinants and associated outcomes. Clin J Am Soc Nephrol. 2009; 4(5):914-920. [PubMed: 19357245]

6. Burton JO, Jefferies HJ, Selby NM, McIntyre CW. Hemodialysis-induced repetitive myocardial injury results in global and segmental reduction in systolic cardiac function. Clin J Am Soc Nephrol. 2009; 4(12):1925-1931. [PubMed: 19808220]

7. Eldehni MT, Odudu A, McIntyre CW. Randomized Clinical Trial of Dialysate Cooling and Effects on Brain White Matter. J Am Soc Nephrol. 2014; 24(4):957-965.

8. McIntyre CW, Harrison LE, Eldehni MT, et al. Circulating endotoxemia: a novel factor in systemic inflammation and cardiovascular disease in chronic kidney disease. Clin J Am Soc Nephrol. 2011; 6(1):133-141. [PubMed: 20876680]

9. Centers for Medicare and Medicaid Services. Proposed Measure Specifications for the PY 2019 ESRD QIP. Available at https://www.cms.gov/Medicare/Quality-Initiatives-Patient-AssessmentInstruments/ESRDQIP/Downloads/ESRDQIPSummaryPaymentYears2014-2018.pdf. Accessed February 4, 2016

10. Centers for Medicare and Medicaid Services. Release of Fiscal Year 2016 End Stage Renal Disease Core Survey Data Worksheet. 2015. Available at https://www.cms.gov/Medicare/ProviderEnrollment-and-Certification/GuidanceforLawsAndRegulations/Downloads/ESRD-Core-SurveyData-Worksheet.pdf. Accessed February 4, 2016

11. Farrar D, Glauber R. Multicollinearity in regression analysis: the problem revisited. The Review of Economics and Statistics. 1967; 1:92-107.

12. National Kidney Foundation. KDOQI Clinical Practice Guideline for Hemodialysis Adequacy: 2015 Update. Am J Kidney Dis. 2015; 66(5):884-930. [PubMed: 26498416]

13. Agar JW. Personal viewpoint: Limiting maximum ultrafiltration rate as a potential new measure of dialysis adequacy. Hemodial Int. 2016; 20(1):15-21. [PubMed: 25779217]

14. National Quality Forum. Renal Draft Report. Available at https://www.google.com/url? $\mathrm{sa}=\mathrm{t} \& \mathrm{rct}=\mathrm{j} \& \mathrm{q}=\& \mathrm{esrc}=\mathrm{s} \&$ source $=$ web $\& \mathrm{~cd}=1 \& \mathrm{cad}=\mathrm{rja} \&$ uact $=8 \& \mathrm{ved}=0 \mathrm{ahUKEwja}$ c cqlzr7JAhXDP iYKHTQUCHUQFggcMAA\&url=http $\% 3 \mathrm{~A} \% 2 \mathrm{~F} \% 2 \mathrm{Fwww}$.qualityforum.org $\% 2 \mathrm{FProjects} \% 2 \mathrm{Fn}-\mathrm{r}$ $\%$ 2FRenal_Measures

\%2FDraft_Report_for_Comment.aspx\&usg=AFQjCNFGMoefydMrs7WvIqT7_11_3wncjw\&sig2 =f0jP_24ngTVnc9pohVNBA. Accessed February 4, 2016

15. Du Bois D, Du Bois EF. A formula to estimate the approximate surface area if height and weight be known. 1916. Nutrition. 1989; 5(5):303-311. discussion 312-303. [PubMed: 2520314]

16. Noordzij M, Leffondré K, van Stralen KJ, Zoccali C, Dekker FW, Jager KJ. When do we need competing risks methods for survival analysis in nephrology? Nephrol Dial Transplant. 2013; 28(11):2670-2677. [PubMed: 23975843]

17. Schafer JL. Multiple imputation: a primer. Stat Methods Med Res. 1999; 8(1):3-15. [PubMed: 10347857]

18. Vuong Q. Likelihood ratio tests for model selection and non-nested hypotheses. Econometrica. 1989; 57(2):307-334.

19. Robins JM, Hernán MA, Brumback B. Marginal structural models and causal inference in epidemiology. Epidemiology. 2000; 11(5):550-560. [PubMed: 10955408]

20. Hernán MA, Brumback B, Robins JM. Marginal structural models to estimate the causal effect of zidovudine on the survival of HIV-positive men. Epidemiology. 2000; 11(5):561-570. [PubMed: 10955409]

21. Eldehni MT, McIntyre CW. Are there neurological consequences of recurrent intradialytic hypotension? Semin Dial. 2012; 25(3):253-256. [PubMed: 22353138]

22. End Stage Renal Disease (ESRD) Quality Measure Development and Maintenance Hemodialysis Adequacy Clinical Technical Expert Panel Summary Report. Arbor Research Collaborative for 
Health and the University of Michigan Kidney Epidemiology and Cost Center. 2013. Available at http://www.cms.gov/Medicare/Quality-Initiatives-Patient-Assessment-Instruments/MMS/ Downloads/Hemodialysis-Adequacy-TEP-Summary-Report-and-Addendum.pdf. Accessed February 4, 2016

23. Arora N, Chertow GM. Oh! What a tangled web we weave. Clin J Am Soc Nephrol. 2013; 8(7): 1066-1067. [PubMed: 23766364]

24. Assimon MM, Flythe JE. Intradialytic Blood Pressure Abnormalities: The Highs, The Lows and All That Lies Between. Am J Nephrol. 2015; 42(5):337-350. [PubMed: 26584275]

25. Flythe JE, Mangione TW, Brunelli SM, Curhan GC. Patient-Stated Preferences Regarding VolumeRelated Risk Mitigation Strategies for Hemodialysis. Clin J Am Soc Nephrol. 2014; 9(8):14181425. [PubMed: 24903386]

26. Schneditz D, Roob J, Oswald M, et al. Nature and rate of vascular refilling during hemodialysis and ultrafiltration. Kidney Int. 1992; 42(6):1425-1433. [PubMed: 1474776] 
30-day exposure period

Study entry

6/1/2008-

$12 / 31 / 2012$

Assess ultrafiltration rates

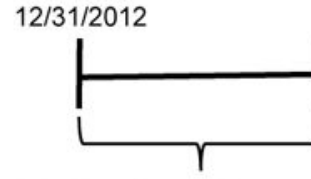

30-day baseline period

1

Follow-up: Outcome assessment

Study end

12/31/2013

Obtain covariates and define

subgroups

Figure 1. Study design schematic

a Source cohort consisted of 337,863 in-center hemodialysis patients with complete age, sex, race and ethnicity data. 


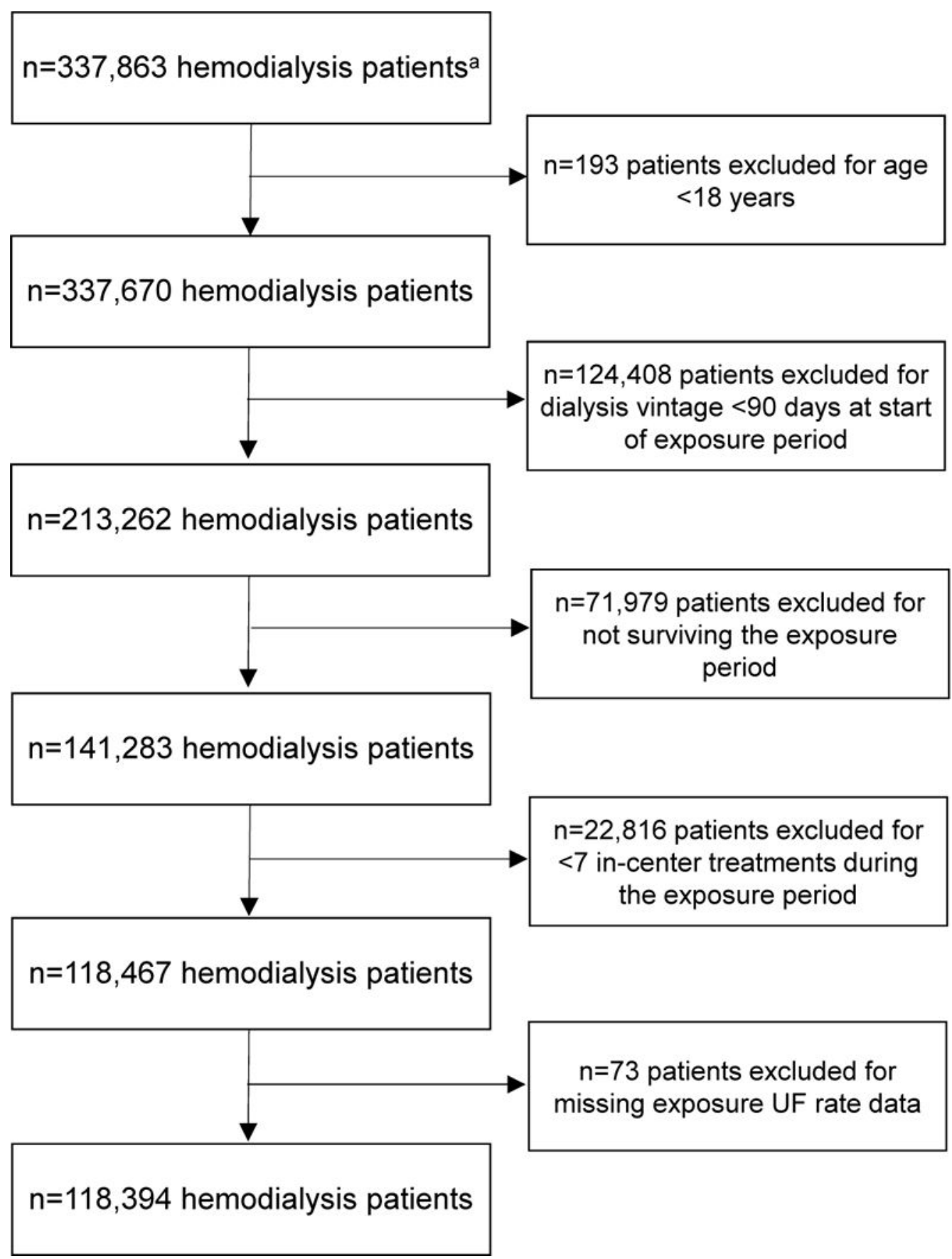

Figure 2.

Flow-chart of cohort selection. 


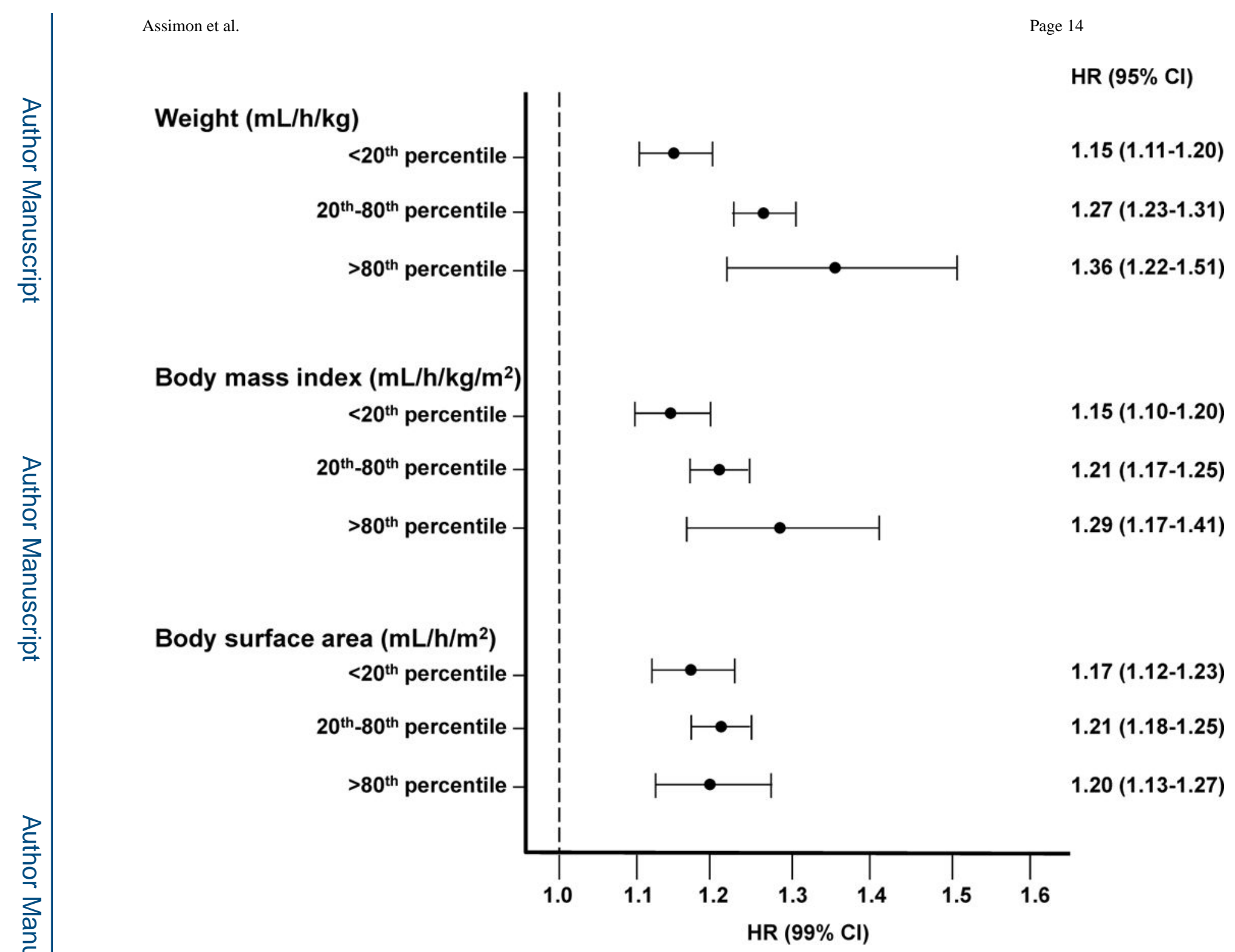

Figure 3. Associations between prescribed ultrafiltration rate and mortality by percentile of postdialysis weight, body mass index and body surface area

Fine and Gray proportional subdistribution hazards regression models with kidney transplantation and dialysis modality change treated as competing risks were used to estimate the ultrafiltration rate and all-cause mortality association comparing mean UF rates $>13 \mathrm{~mL} / \mathrm{h} / \mathrm{kg}$ to those $\leq 3 \mathrm{~mL} / \mathrm{h} / \mathrm{kg}$ within strata of body weight, BMI and BSA (separately). Models were adjusted for age (continuous), sex (female vs. male), race (black vs. nonblack), ethnicity (Hispanic vs. non-Hispanic), dialysis vintage (1-2, 3-4, 25 vs. <1 year), vascular access (graft, fistula vs. catheter), history of heart failure (yes vs. no), history of cardiovascular disease (yes vs. no), history of diabetes (yes vs. no), albumin (3.1-3.5, 3.6$4.0,>4.0$ vs. $3.0 \mathrm{~g} / \mathrm{dL}$ ), creatinine (continuous), phosphorous (4.1-5.0, 5.1-6.0, >6.0 vs. $\leq 4.0 \mathrm{mg} / \mathrm{dL})$, hemoglobin $(10.0-11.9, \geq 12.0 \mathrm{vs} .<10.0 \mathrm{~g} / \mathrm{dL})$, urea reduction ratio (continuous), pre-HD systolic blood pressure (131-150, 151-170,>170 vs. $\triangle 30 \mathrm{mmHg}$ ), and missed sessions ( 23 vs. $<3$ ). 
Post-dialysis weight was used to calculate normalized UF rates for weight, BMI and BSA. $20^{\text {th }} / 80^{\text {th }}$ percentile for post-weight $=60.9 / 95.3 \mathrm{~kg} ; 21.8 / 32.8 \mathrm{~kg} / \mathrm{m}^{2}$ for BMI; $1.66 / 2.10 \mathrm{~m}^{2}$ for BSA. $80^{\text {th }}$ percentile for UF rate normalized to BMI $=37 \mathrm{~mL} / \mathrm{h} /\left(\mathrm{kg} / \mathrm{m}^{2}\right)$; UF rate normalized to BSA $=500 \mathrm{~mL} / \mathrm{h} / \mathrm{m}^{2} .80^{\text {th }}$ percentile selected for BMI and BSA based on 13 $\mathrm{mL} / \mathrm{h} / \mathrm{kg}$ being the $80^{\text {th }}$ percentile of UF rate when normalized to post-HD weight.

Abbreviations: $\mathrm{HR}=$ hazard ratio, $\mathrm{CI}=$ confidence interval, $\mathrm{HD}=$ hemodialysis 
Table 1

Baseline characteristics across prescribed ultrafiltration rate groups.

\begin{tabular}{|c|c|c|c|c|}
\hline & \multirow[b]{2}{*}{ Total $(\mathrm{N}=118,394)^{b}$} & \multicolumn{3}{|c|}{ 30-d mean prescribed UF rate } \\
\hline & & $\begin{array}{c}<10 \mathrm{~mL} / \mathrm{h} / \mathrm{kg} \\
\left(\mathrm{n}=69,865[59.0 \%]^{b}\right.\end{array}$ & $\begin{array}{c}10-13 \mathrm{~mL} / \mathrm{h} / \mathrm{kg} \\
(\mathrm{n}=26,794[22.6 \%])^{b}\end{array}$ & $\begin{array}{c}>13 \mathrm{~mL} / \mathrm{h} / \mathrm{kg} \\
(\mathrm{n}=21,735[18.4 \%])^{b}\end{array}$ \\
\hline \multicolumn{5}{|l|}{ UF rate } \\
\hline $\mathrm{pmL} / \mathrm{h} / \mathrm{kg}$ & $9.4 \pm 4.3$ & $6.6 \pm 2.5$ & $11.4 \pm 0.9$ & $16.0 \pm 2.9$ \\
\hline $\mathrm{mL} / \mathrm{h} / \mathrm{kg} / \mathrm{m}^{2}$ & $27.2 \pm 13.2(\mathrm{n}=118,215)$ & $19.5 \pm 8.5(\mathrm{n}=69,743)$ & $32.8 \pm 6.4(\mathrm{n}=26,765)$ & $45.0 \pm 10.8(\mathrm{n}=21,707)$ \\
\hline $\mathrm{mL} / \mathrm{h} / \mathrm{m}^{2}$ & $377.2 \pm 154.2(\mathrm{n}=118,215)$ & $\begin{array}{c}286.3 \pm 107.7 \\
(\mathrm{n}=69,768)\end{array}$ & $\begin{array}{c}451.1 \pm 70.0 \\
(\mathrm{n}=26,765)\end{array}$ & $\begin{array}{c}578.3 \pm 111.8 \\
(\mathrm{n}=21,707)\end{array}$ \\
\hline Age (y) & $61 \pm 15$ & $62 \pm 15$ & $61 \pm 15$ & $58 \pm 16$ \\
\hline Female sex & $53,307(45.0)$ & $30,964(44.3)$ & $11,554(43.1)$ & $10,789(49.6)$ \\
\hline Black race & $45,289(38.3)$ & $28,584(40.9)$ & $9,713(36.3)$ & $6,992(32.2)$ \\
\hline Hispanic ethnicity & $19,520(16.5)$ & $9,823(14.1)$ & $5,108(19.1)$ & $4,589(21.1)$ \\
\hline History of heart failure & $31,534(26.6)$ & $16,775(24.0)$ & $7,911(29.5)$ & $6,848(31.5)$ \\
\hline History of CVD & $66,988(56.6)$ & $37,999(54.4)$ & $15,864(59.2)$ & $13,125(60.4)$ \\
\hline History of diabetes & $61,721(52.1)$ & $36,085(51.6)$ & $14,467(54.0)$ & $11,169(51.4)$ \\
\hline \multicolumn{5}{|l|}{ Dialysis vintage } \\
\hline$<1 \mathrm{y}$ & $25,283(21.4)$ & $16,874(24.2)$ & $4,963(18.5)$ & $3,446(15.9)$ \\
\hline $1-2 \mathrm{y}$ & $39,411(33.3)$ & $23,995(34.3)$ & $8,788(32.8)$ & $6,628(30.5)$ \\
\hline $3-4 y$ & $22,718(19.2)$ & $12,842(18.4)$ & $5,404(20.2)$ & $4,472(20.6)$ \\
\hline $25 \mathrm{y}$ & $30,982(26.2)$ & $16,154(23.1)$ & $7,639(28.5)$ & $7,189(33.1)$ \\
\hline \multicolumn{5}{|l|}{ Vascular access } \\
\hline Graft & $25,743(21.7)$ & $14,323(20.5)$ & $6,184(23.1)$ & $5,236(24.1)$ \\
\hline Fistula & $61,991(52.4)$ & $35,226(50.4)$ & $14,784(55.2)$ & $11,981(55.1)$ \\
\hline Catheter & $30,660(25.9)$ & $20,316(29.1)$ & $5,826(21.7)$ & $4,518(20.8)$ \\
\hline Post-HD weight (kg) & $79.2 \pm 22.4$ & $84.6 \pm 23.7$ & $75.6 \pm 18.3$ & $73.5 \pm 6.5$ \\
\hline IDWG (kg) & $2.9 \pm 2.2$ & $2.5 \pm 2.1$ & $3.3 \pm 2.0$ & $3.6 \pm 2.2$ \\
\hline $\operatorname{BMI}\left(\mathrm{kg} / \mathrm{m}^{2}\right)$ & $27.7 \pm 7.3(n=118,215)$ & $29.3 \pm 7.8(\mathrm{n}=69,743)$ & $26.6 \pm 6.1(n=26,765)$ & $23.9 \pm 5.1(n=21,707)$ \\
\hline $\operatorname{BSA}\left(\mathrm{m}^{2}\right)$ & $1.9 \pm 0.3(\mathrm{n}=118,215)$ & $2.0 \pm 0.3(\mathrm{n}=69,768)$ & $1.9 \pm 0.2(\mathrm{n}=26,765)$ & $1.7 \pm 0.2(\mathrm{n}=21,707)$ \\
\hline Prescribed session duration (min) & $218 \pm 36$ & $223 \pm 39$ & $214 \pm 28$ & $205 \pm 28$ \\
\hline \multicolumn{5}{|l|}{ Pre-HD SBP } \\
\hline$\leq 30 \mathrm{~m} \mathrm{Hg}$ & $28,766(24.3)$ & $17,419(24.9)$ & $6,403(23.9)$ & $4,944(22.7)$ \\
\hline $131-150 \mathrm{~mm} \mathrm{Hg}$ & $34,102(28.8)$ & $20,217(28.9)$ & $7,783(29.0)$ & $6,102(28.1)$ \\
\hline $151-170 \mathrm{~mm} \mathrm{Hg}$ & $30,279(25.6)$ & $17,640(25.2)$ & $6,934(25.9)$ & $5,705(26.2)$ \\
\hline$\geq 171 \mathrm{~mm} \mathrm{Hg}$ & $25,247(21.3)$ & $14,589(20.9)$ & $5,674(21.2)$ & $4,984(22.9)$ \\
\hline Missed sessions $\geq 3$ & $23,590(19.9)$ & $13,590(19.5)$ & $5,183(19.3)$ & $4,817(22.2)$ \\
\hline \multicolumn{5}{|l|}{ Albumin $c$} \\
\hline $33.0 \mathrm{~g} / \mathrm{dL}$ & $6,390(5.4)$ & $3,932(5.6)$ & $1,216(4.5)$ & $1,242(5.7)$ \\
\hline $3.1-3.5 \mathrm{~g} / \mathrm{dL}$ & $19,852(16.8)$ & $11,829(16.9)$ & 4,255 (15.9) & $3,768(17.3)$ \\
\hline $3.6-4.0 \mathrm{~g} / \mathrm{dL}$ & $56,005(47.3)$ & $33,335(47.7)$ & $12,785(47.7)$ & $9,885(45.5)$ \\
\hline$>4.0 \mathrm{~g} / \mathrm{dL}$ & $36,147(30.5)$ & $20,769(29.7)$ & $8,538(31.9)$ & $6,840(31.5)$ \\
\hline
\end{tabular}




\begin{tabular}{|c|c|c|c|c|}
\hline & \multirow[b]{2}{*}{ Total $(\mathrm{N}=118,394)^{b}$} & \multicolumn{3}{|c|}{ 30-d mean prescribed UF rate } \\
\hline & & $\begin{array}{c}<10 \mathrm{~mL} / \mathrm{h} / \mathrm{kg} \\
\left(\mathrm{n}=69,865[59.0 \%]^{b}\right.\end{array}$ & $\begin{array}{c}10-13 \mathrm{~mL} / \mathrm{h} / \mathrm{kg} \\
(\mathrm{n}=26,794[22.6 \%])^{b}\end{array}$ & $\begin{array}{c}>13 \mathrm{~mL} / \mathrm{h} / \mathrm{kg} \\
(\mathrm{n}=21,735[18.4 \%])^{b}\end{array}$ \\
\hline Serum sodium $(\mathrm{mEq} / \mathrm{L})^{c}$ & $138.2 \pm 2.1$ & $138.4 \pm 2.0$ & $138.2 \pm 2.1$ & $137.8 \pm 2.3$ \\
\hline Creatinine $(\mathrm{mg} / \mathrm{dL})^{c}$ & $8.3 \pm 3.1$ & $8.1 \pm 3.1$ & $8.6 \pm 3.1$ & $8.6 \pm 3.1$ \\
\hline \multicolumn{5}{|l|}{ Phosphorous ${ }^{c}$} \\
\hline$\$ 4.0 \mathrm{mg} / \mathrm{dL}$ & $23,431(19.8)$ & $14,849(21.3)$ & $4,815(18.0)$ & 3,767 (17.3) \\
\hline $4.1-5.0 \mathrm{mg} / \mathrm{dL}$ & $33,958(28.7)$ & $20,981(30.0)$ & $7,553(28.2)$ & $5,424(25.0)$ \\
\hline $5.1-6.0 \mathrm{mg} / \mathrm{dL}$ & $29,464(24.9)$ & $17,376(24.9)$ & $6,754(25.2)$ & $5,334(24.5)$ \\
\hline$>6.0 \mathrm{mg} / \mathrm{dL}$ & $31,541(26.6)$ & $16,659(23.8)$ & $7,672(28.6)$ & $7,210(33.2)$ \\
\hline \multicolumn{5}{|l|}{ Hemoglobin $^{c}$} \\
\hline$<10.0 \mathrm{~g} / \mathrm{dL}$ & $12,805(10.8)$ & $7,373(10.6)$ & $2,713(10.1)$ & $2,719(12.5)$ \\
\hline $10.0-11.9 \mathrm{~g} / \mathrm{dL}$ & $56,405(47.6)$ & $33,526(48.0)$ & $12,680(47.3)$ & $10,199(46.9)$ \\
\hline$\geq 12.0 \mathrm{~g} / \mathrm{dL}$ & $49,184(41.5)$ & $28,966(41.5)$ & $11,401(42.6)$ & 8,817 (40.6) \\
\hline Urea reduction ratio $(\%)^{c}$ & $73.0 \pm 6.8$ & $72.8 \pm 7.0$ & $73.2 \pm 6.5$ & $73.5 \pm 6.5$ \\
\hline
\end{tabular}

Note: Values for categorical variables are given as number (percentage); for continuous variables, as mean \pm standard deviation.

$b_{\text {Total n except where noted. }}$

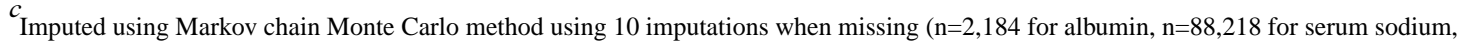
$\mathrm{n}=7,473$ for creatinine, $\mathrm{n}=1,430$ for phosphorus, $\mathrm{n}=627$ for hemoglobin, and $\mathrm{n}=1,642$ for urea reduction ratio).

Abbreviations: BMI, body mass index; BSA, body surface area; $\mathrm{CVD}=$ cardiovascular disease, $\mathrm{HD}=$ hemodialysis, IDWG=interdialytic weight gain, $\mathrm{SBP}=$ systolic blood pressure, $\mathrm{UF}=$ ultrafiltration. 


\section{Table 2}

Associations between prescribed ultrafiltration rate and all-cause mortality among all patients and patients with longer dialysis vintage.

\begin{tabular}{|c|c|c|c|}
\hline & $\mathrm{n}(\%)$ & Unadjusted HR (95\% CI) & Adjusted $^{b}$ HR $(95 \%$ CI \\
\hline \multicolumn{4}{|c|}{ Full Cohort $(\mathrm{N}=118,394)$} \\
\hline \multicolumn{4}{|c|}{ Mean UF rate dichotomized at $10 \mathrm{~mL} / \mathrm{h} / \mathrm{kg}$} \\
\hline$\unlhd 10 \mathrm{~mL} / \mathrm{h} / \mathrm{kg}$ & $69,865(59.0)$ & 1.00 (reference) & 1.00 (reference) \\
\hline$>10 \mathrm{~mL} / \mathrm{h} / \mathrm{kg}$ & $48,529(41.0)$ & $1.10(1.08-1.12)$ & $1.22(1.20-1.24)$ \\
\hline \multicolumn{4}{|c|}{ Mean UF rate dichotomized at $13 \mathrm{~mL} / \mathrm{h} / \mathrm{kg}$} \\
\hline$\unlhd 3 \mathrm{~mL} / \mathrm{h} / \mathrm{kg}$ & $96,659(81.6)$ & 1.00 (reference) & 1.00 (reference) \\
\hline$>13 \mathrm{~mL} / \mathrm{h} / \mathrm{kg}$ & $21,735(18.4)$ & $1.15(1.12-1.17)$ & $1.31(1.28-1.34)$ \\
\hline \multicolumn{4}{|c|}{ Mean UF rate categorized } \\
\hline$<10 \mathrm{~mL} / \mathrm{h} / \mathrm{kg}$ & $69,865(59.0)$ & 1.00 (reference) & 1.00 (reference) \\
\hline $10-13 \mathrm{~mL} / \mathrm{h} / \mathrm{kg}$ & $26,794(22.6)$ & $1.05(1.03-1.07)$ & $1.12(1.10-1.15)$ \\
\hline$>13 \mathrm{~mL} / \mathrm{h} / \mathrm{kg}$ & $21,735(18.4)$ & $1.16(1.14-1.19)$ & $1.35(1.32-1.39)$ \\
\hline \multicolumn{4}{|c|}{ Restricted Cohort: Dialysis Vintage $\geq \underset{4}{Y}(\mathrm{n}=40,706)$} \\
\hline \multicolumn{4}{|c|}{ Mean UF rate dichotomized at $10 \mathrm{~mL} / \mathrm{h} / \mathrm{kg}$} \\
\hline$\unlhd 0 \mathrm{~mL} / \mathrm{h} / \mathrm{kg}$ & $21,470(52.7)$ & 1.00 (reference) & 1.00 (reference) \\
\hline$>10 \mathrm{~mL} / \mathrm{h} / \mathrm{kg}$ & $19,236(47.3)$ & $1.03(1.00-1.06)$ & $1.19(1.15-1.23)$ \\
\hline \multicolumn{4}{|c|}{ Mean UF rate dichotomized at $13 \mathrm{~mL} / \mathrm{h} / \mathrm{kg}$} \\
\hline$\unlhd 3 \mathrm{~mL} / \mathrm{h} / \mathrm{kg}$ & $31,488(77.4)$ & 1.00 (reference) & 1.00 (reference) \\
\hline$>13 \mathrm{~mL} / \mathrm{h} / \mathrm{kg}$ & $9,218(22.6)$ & $1.05(1.02-1.09)$ & $1.26(1.21-1.30)$ \\
\hline \multicolumn{4}{|c|}{ Mean UF rate categorized } \\
\hline$<10 \mathrm{~mL} / \mathrm{h} / \mathrm{kg}$ & $21,470(52.7)$ & 1.00 (reference) & 1.00 (reference) \\
\hline $10-13 \mathrm{~mL} / \mathrm{h} / \mathrm{kg}$ & $10,018(24.6)$ & $1.00(0.97-1.04)$ & $1.10(1.06-1.15)$ \\
\hline$>13 \mathrm{~mL} / \mathrm{h} / \mathrm{kg}$ & $9,218(22.6)$ & $1.05(1.02-1.10)$ & $1.30(1.25-1.35)$ \\
\hline
\end{tabular}

Note: Fine and Gray proportional subdistribution hazards regression models with kidney transplantation and dialysis modality change treated as competing risks were used to estimate the ultrafiltration rate and all-cause mortality association.

${ }^{b}$ Adjusted for baseline age (continuous), sex (female vs. male), race (black vs. non-black), ethnicity (Hispanic vs. non-Hispanic), dialysis vintage $(1-2,3-4, \geq 5$ vs. $<1$ year), vascular access (graft, fistula vs. catheter), history of heart failure (yes vs. no), history of cardiovascular disease (yes vs. no), history of diabetes (yes vs. no), albumin $(3.1-3.5,3.6-4.0,>4.0 \mathrm{vs.} 33.0 \mathrm{~g} / \mathrm{dL}$ ), creatinine (continuous), phosphorous $(4.1-5.0,5.1-6.0,>6.0$ vs. $\leq 4.0 \mathrm{mg} / \mathrm{dL}$ ), hemoglobin $(10.0-11.9, \geq 12.0 \mathrm{vs} .<10.0 \mathrm{~g} / \mathrm{dL}$ ), urea reduction ratio (continuous), pre-hemodialysis systolic blood pressure (131$150,151-170,>170$ vs. $₫ 30 \mathrm{mmHg}$ ), missed sessions ( $>3 \mathrm{vs}$. <3). Subgroups of interest were excluded from the adjustments listed previously where applicable.

Abbreviations: $\mathrm{HR}=$ hazard ratio, $\mathrm{CI}=$ confidence interval, $\mathrm{UF}=$ ultrafiltration. 
Table 3

Associations between continuous and finely categorized prescribed ultrafiltration rate and all-cause mortality.

\begin{tabular}{lccc}
\hline & & \multicolumn{2}{c}{ HR (95\% CI) } \\
\cline { 3 - 4 } & $\mathbf{n}(\%)$ & Unadjusted & Adjusted $^{b}$ \\
\hline Mean UF rate, $\mathrm{mL} / \mathrm{h} / \mathrm{kg}$ & $118,394(100.0 \%)$ & $1.01(1.01-1.02)$ & $1.03(1.02-1.03)$ \\
Mean UF rate & & & \\
$<6 \mathrm{~mL} / \mathrm{h} / \mathrm{kg}$ & $23,813(20.1 \%)$ & 1.00 (reference) & 1.00 (reference) \\
$6-<8 \mathrm{~mL} / \mathrm{h} / \mathrm{kg}$ & $21,729(18.4 \%)$ & $0.99(0.96-1.02)$ & $1.03(1.00-1.07)$ \\
$8-<10 \mathrm{~mL} / \mathrm{h} / \mathrm{kg}$ & $24,323(20.5 \%)$ & $1.01(0.98-1.04)$ & $1.09(1.06-1.12)$ \\
$10-<12 \mathrm{~mL} / \mathrm{h} / \mathrm{kg}$ & $19,457(16.4 \%)$ & $1.04(1.01-1.07)$ & $1.15(1.12-1.19)$ \\
$12-<14 \mathrm{~mL} / \mathrm{h} / \mathrm{kg}$ & $13,086(11.1 \%)$ & $1.08(1.05-1.12)$ & $1.23(1.18-1.27)$ \\
$\geq 14 \mathrm{~mL} / \mathrm{h} / \mathrm{kg}$ & $15,986(13.5 \%)$ & $1.19(1.15-1.23)$ & $1.43(1.39-1.48)$ \\
\hline
\end{tabular}

Note: Fine and Gray proportional subdistribution hazards regression models with kidney transplantation and dialysis modality change treated as competing risks were used to estimate the ultrafiltration rate and all-cause mortality association.

\section{$b$}

djusted for baseline age (continuous), sex (female vs. male), race (black vs. non-black), ethnicity (Hispanic vs. non-Hispanic), dialysis vintage (1-2, 3-4, 25 vs. <1 year), vascular access (graft, fistula vs. catheter), history of heart failure (yes vs. no), history of cardiovascular disease (yes vs. no), history of diabetes (yes vs. no), albumin (3.1-3.5, 3.6-4.0, >4.0 vs. $3.0 \mathrm{~g} / \mathrm{dL}$ ), creatinine (continuous), phosphorous (4.1-5.0, 5.1-6.0, >6.0 vs. $\leq 4.0 \mathrm{mg} / \mathrm{dL}$ ), hemoglobin $(10.0-11.9, \geq 12.0 \mathrm{vs}$. $<10.0 \mathrm{~g} / \mathrm{dL})$, urea reduction ratio (continuous), pre-hemodialysis systolic blood pressure (131$150,151-170,>170$ vs. $\leq 30 \mathrm{mmHg}$ ), missed sessions ( 23 vs. $<3$ ).

Abbreviations: $\mathrm{HR}=$ hazard ratio, $\mathrm{CI}=$ confidence interval, $\mathrm{UF}=$ ultrafiltration. 
Table 4

Associations between prescribed ultrafiltration rate and mortality within subgroups of interest.

\begin{tabular}{|c|c|c|c|}
\hline Sex & Female $(n=53,307)$ & Male $(n=65,087)$ & $\mathrm{P}$ for interaction $b$ \\
\hline Mean UF rate dichotomized at $10 \mathrm{~mL} / \mathrm{h} / \mathrm{kg}$ & & & $<0.001$ \\
\hline$\leq 10 \mathrm{~mL} / \mathrm{h} / \mathrm{kg}$ & 1.00 (reference) & 1.00 (reference) & \\
\hline$>10 \mathrm{~mL} / \mathrm{h} / \mathrm{kg}$ & $1.26(1.23-1.30)$ & $1.18(1.15-1.21)$ & \\
\hline Mean UF rate dichotomized at $13 \mathrm{~mL} / \mathrm{h} / \mathrm{kg}$ & & & 0.2 \\
\hline$\unlhd 3 \mathrm{~mL} / \mathrm{h} / \mathrm{kg}$ & 1.00 (reference) & 1.00 (reference) & \\
\hline$>13 \mathrm{~mL} / \mathrm{h} / \mathrm{kg}$ & $1.33(1.29-1.37)$ & $1.29(1.25-1.33)$ & \\
\hline Mean UF rate continuous $(\mathrm{mL} / \mathrm{h} / \mathrm{kg})$ & $1.03(1.03-1.03)$ & $1.02(1.02-1.03)$ & 0.004 \\
\hline Race & Non-Black $(n=73,105)$ & Black $(n=45,289)$ & $\mathrm{P}$ for interaction $b$ \\
\hline Mean UF rate dichotomized at $10 \mathrm{~mL} / \mathrm{h} / \mathrm{kg}$ & & & 0.6 \\
\hline$\leq 10 \mathrm{~mL} / \mathrm{h} / \mathrm{kg}$ & 1.00 (reference) & 1.00 (reference) & \\
\hline$>10 \mathrm{~mL} / \mathrm{h} / \mathrm{kg}$ & $1.21(1.19-1.24)$ & $1.23(1.19-1.27)$ & \\
\hline Mean UF rate dichotomized at $13 \mathrm{~mL} / \mathrm{h} / \mathrm{kg}$ & & & 0.004 \\
\hline$\unlhd 3 \mathrm{~mL} / \mathrm{h} / \mathrm{kg}$ & 1.00 (reference) & 1.00 (reference) & \\
\hline$>13 \mathrm{~mL} / \mathrm{h} / \mathrm{kg}$ & $1.28(1.24-1.31)$ & $1.38(1.32-1.43)$ & \\
\hline Mean UF rate continuous $(\mathrm{mL} / \mathrm{h} / \mathrm{kg})$ & $1.03(1.02-1.03)$ & $1.03(1.03-1.03)$ & 0.2 \\
\hline Ethnicity & Non-Hispanic $(n=98,874)$ & Hispanic $(n=19,520)$ & $\mathrm{P}$ for interaction $b$ \\
\hline Mean UF rate dichotomized at $10 \mathrm{~mL} / \mathrm{h} / \mathrm{kg}$ & & & 0.1 \\
\hline$\leq 10 \mathrm{~mL} / \mathrm{h} / \mathrm{kg}$ & 1.00 (reference) & 1.00 (reference) & \\
\hline$>10 \mathrm{~mL} / \mathrm{h} / \mathrm{kg}$ & $1.23(1.20-1.25)$ & $1.17(1.12-1.23)$ & \\
\hline Mean UF rate dichotomized at $13 \mathrm{~mL} / \mathrm{h} / \mathrm{kg}$ & & & 0.002 \\
\hline$\unlhd 3 \mathrm{~mL} / \mathrm{h} / \mathrm{kg}$ & 1.00 (reference) & 1.00 (reference) & \\
\hline$>13 \mathrm{~mL} / \mathrm{h} / \mathrm{kg}$ & $1.33(1.29-1.36)$ & $1.20(1.14-1.27)$ & \\
\hline Mean UF rate continuous $(\mathrm{mL} / \mathrm{h} / \mathrm{kg})$ & $1.03(1.02-1.03)$ & $1.02(1.01-1.03)$ & 0.03 \\
\hline Dialysis Vintage & $<4$ y $(n=77,688)$ & $\geq 4$ y $(n=40,706)$ & P for interaction $b$ \\
\hline Mean UF rate dichotomized at $10 \mathrm{~mL} / \mathrm{h} / \mathrm{kg}$ & & & $<0.001$ \\
\hline$\leq 10 \mathrm{~mL} / \mathrm{h} / \mathrm{kg}$ & 1.00 (reference) & 1.00 (reference) & \\
\hline$>10 \mathrm{~mL} / \mathrm{h} / \mathrm{kg}$ & $1.17(1.13-1.21)$ & $1.25(1.22-1.28)$ & \\
\hline Mean UF rate dichotomized at $13 \mathrm{~mL} / \mathrm{h} / \mathrm{kg}$ & & & $<0.001$ \\
\hline$\leq 3 \mathrm{~mL} / \mathrm{h} / \mathrm{kg}$ & 1.00 (reference) & 1.00 (reference) & \\
\hline$>13 \mathrm{~mL} / \mathrm{h} / \mathrm{kg}$ & $1.23(1.19-1.28)$ & $1.37(1.33-1.41)$ & \\
\hline Mean UF rate continuous $(\mathrm{mL} / \mathrm{h} / \mathrm{kg})$ & $1.03(1.02-1.03)$ & $1.02(1.02-1.03)$ & 0.007 \\
\hline Session Duration & $<4 h(n=78,504)$ & $\geq 4 h(n=39,890)$ & $\mathrm{P}$ for interaction $b$ \\
\hline Mean UF rate dichotomized at $10 \mathrm{~mL} / \mathrm{h} / \mathrm{kg}$ & & & 0.9 \\
\hline$\leq 1 \mathrm{~mL} / \mathrm{h} / \mathrm{kg}$ & 1.00 (reference) & 1.00 (reference) & \\
\hline$>10 \mathrm{~mL} / \mathrm{h} / \mathrm{kg}$ & $1.22(1.20-1.25)$ & $1.23(1.19-1.27)$ & \\
\hline Mean UF rate dichotomized at $13 \mathrm{~mL} / \mathrm{h} / \mathrm{kg}$ & & & 0.02 \\
\hline
\end{tabular}




\begin{tabular}{|c|c|c|c|}
\hline$\leq 3 \mathrm{~mL} / \mathrm{h} / \mathrm{kg}$ & 1.00 (reference) & 1.00 (reference) & \\
\hline$>13 \mathrm{~mL} / \mathrm{h} / \mathrm{kg}$ & $1.30(1.26-1.33)$ & $1.39(1.32-1.46)$ & \\
\hline Mean UF rate continuous (mL/h/kg) & $1.03(1.02-1.03)$ & $1.03(1.02-1.03)$ & 0.09 \\
\hline Post-HD Weight & $<2 O^{\text {th }}$ percentile $^{\mathcal{c}}(n=23,524)$ & $>8 O^{\text {th }}$ percentile $^{\mathcal{c}}(n=23,646)$ & $\mathrm{P}$ for interaction $b$ \\
\hline Mean UF rate dichotomized at $10 \mathrm{~mL} / \mathrm{h} / \mathrm{kg}$ & & & 0.2 \\
\hline$\unlhd 0 \mathrm{~mL} / \mathrm{h} / \mathrm{kg}$ & 1.00 (reference) & 1.00 (reference) & \\
\hline$>10 \mathrm{~mL} / \mathrm{h} / \mathrm{kg}$ & $1.14(1.10-1.19)$ & $1.22(1.16-1.29)$ & \\
\hline Mean UF rate dichotomized at $13 \mathrm{~mL} / \mathrm{h} / \mathrm{kg}$ & & & $<0.001$ \\
\hline$\leq 3 \mathrm{~mL} / \mathrm{h} / \mathrm{kg}$ & 1.00 (reference) & 1.00 (reference) & \\
\hline$>13 \mathrm{~mL} / \mathrm{h} / \mathrm{kg}$ & $1.15(1.11-1.20)$ & $1.36(1.22-1.51)$ & \\
\hline Mean UF rate continuous (mL/h/kg) & $1.01(1.01-1.02)$ & $1.02(1.02-1.03)$ & $<0.001$ \\
\hline
\end{tabular}

Except where indicated, values shown are Adjusted $^{a}$ HR (95\% confidence interval).

a Fine and Gray proportional subdistribution hazards regression models with kidney transplantation and dialysis modality change treated as competing risks were used to estimate the ultrafiltration rate and all-cause mortality association. Adjusted for age (continuous), sex (female vs. male), race (black vs. non-black), ethnicity (Hispanic vs. non-Hispanic), dialysis vintage (1-2, 3-4, $\geq 5$ vs. <1 year), vascular access (graft, fistula vs. catheter), history of heart failure (yes vs. no), history of cardiovascular disease (yes vs. no), history of diabetes (yes vs. no), albumin (3.1-3.5, $3.6-4.0,>4.0$ vs. $33.0 \mathrm{~g} / \mathrm{dL}$ ), creatinine (continuous), phosphorous (4.1-5.0, 5.1-6.0, >6.0 vs. $\leq 4.0 \mathrm{mg} / \mathrm{dL})$, hemoglobin (10.0-11.9, $\geq 12.0 \mathrm{vs.}$ $<10.0 \mathrm{~g} / \mathrm{dL}$ ), urea reduction ratio (continuous), pre-HD systolic blood pressure (131-150, 151-170, >170 vs. $\leq 30 \mathrm{mmHg}$ ), missed sessions ( $\geq 3 \mathrm{vs}$. $<3$ ). Effect modifiers of interest were excluded from the adjustments listed above.

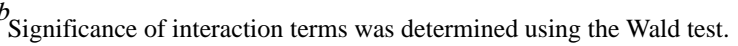

$c_{\text {Post-HD weight } 20^{\text {th }}}$ percentile $=60.9 \mathrm{~kg}$ and $80^{\text {th }}$ percentile $=95.3 \mathrm{~kg}$. The $20^{\text {th }}-80^{\text {th }}$ percentile was included in the model but is not shown.

Abbreviations: Abbreviations: $\mathrm{HR}=$ hazard ratio, $\mathrm{CI}=$ confidence interval, $\mathrm{UF}=$ ultrafiltration, $\mathrm{HD}=$ hemodialysis, pct=percentile. 


\section{Table 5}

Associations between prescribed ultrafiltration rate and mortality overall and by percentile of post-HD weight in patients with prescribed session durations $\geq 4$ hours.

\begin{tabular}{|c|c|c|c|c|}
\hline & \multirow[b]{2}{*}{ All } & \multicolumn{3}{|c|}{ Post-HD weight } \\
\hline & & $\begin{array}{c}<20^{\text {th }} \text { percentile: }<70.9 \\
\text { kg }\end{array}$ & $\begin{array}{l}20^{\text {th }}-80^{\text {th }} \text { percentile: } \\
70.9-110.2 \mathrm{~kg}\end{array}$ & $>80$ th percentile: $>110.2 \mathrm{~kg}$ \\
\hline No. of patients & 39,890 & 7,925 & 24,009 & 7,956 \\
\hline IDWG (kg) & $3.5 \pm 2.3$ & $2.8 \pm 2.2$ & $3.4 \pm 2.2$ & $4.3 \pm 2.4$ \\
\hline Prescribed session duration (min) & $253 \pm 34$ & $247 \pm 31$ & $250 \pm 31$ & $265 \pm 42$ \\
\hline \multicolumn{5}{|l|}{ Associations ${ }^{* *}$} \\
\hline \multicolumn{5}{|l|}{$\begin{array}{l}\text { Mean UF rate dichotomized at } 10 \\
\mathrm{~mL} / \mathrm{h} / \mathrm{kg}\end{array}$} \\
\hline$\unlhd 0 \mathrm{~mL} / \mathrm{h} / \mathrm{kg}$ & 1.00 (reference) & 1.00 (reference) & 1.00 (reference) & 1.00 (reference) \\
\hline$>10 \mathrm{~mL} / \mathrm{h} / \mathrm{kg}$ & $1.23(1.18-1.27)$ & $1.08(1.01-1.16)^{*}$ & $1.18(1.13-1.24)^{*}$ & $1.39(1.24-1.55)^{*}$ \\
\hline \multicolumn{5}{|l|}{$\begin{array}{l}\text { Mean UF rate dichotomized at } 13 \\
\mathrm{~mL} / \mathrm{h} / \mathrm{kg}\end{array}$} \\
\hline$\unlhd 3 \mathrm{~mL} / \mathrm{h} / \mathrm{kg}$ & 1.00 (reference) & 1.00 (reference) & 1.00 (reference) & 1.00 (reference) \\
\hline$>13 \mathrm{~mL} / \mathrm{h} / \mathrm{kg}$ & $1.38(1.31-1.45)$ & $1.21(1.12-1.31)^{*}$ & $1.32(1.23-1.43)^{*}$ & $1.76(1.41-2.18)^{*}$ \\
\hline \multicolumn{5}{|l|}{ Mean UF rate categorized } \\
\hline$<10 \mathrm{~mL} / \mathrm{h} / \mathrm{kg}$ & 1.00 (reference) & 1.00 (reference) & 1.00 (reference) & 1.00 (reference) \\
\hline $10-13 \mathrm{~mL} / \mathrm{h} / \mathrm{kg}$ & $1.14(1.09-1.18)$ & $0.98(0.90-1.06)^{*}$ & $1.12(1.06-1.18)^{*}$ & $1.31(1.16-1.48)^{*}$ \\
\hline$>13 \mathrm{~mL} / \mathrm{h} / \mathrm{kg}$ & $1.42(1.35-1.50)$ & $1.20(1.11-1.31)^{*}$ & $1.36(1.26-1.48)^{*}$ & $1.81(1.45-2.25)^{*}$ \\
\hline
\end{tabular}

Note: Unless otherwise indicated, values are given as mean \pm standard deviation.

Interaction term significant at $\mathrm{p}<0.01$.

Values given as adjusted ${ }^{a}$ HR $(95 \% \mathrm{CI})$

${ }^{a}$ Fine and Gray proportional subdistribution hazards regression models with kidney transplantation and dialysis modality change treated as a competing risks were used to estimate the ultrafiltration rate and all-cause mortality association. Models are adjusted for age (continuous), sex (female vs. male), race (black vs. non-black), ethnicity (Hispanic vs. non-Hispanic), dialysis vintage (1-2, 3-4, 25 vs. <1 year), vascular access (graft, fistula vs. catheter), history of heart failure (yes vs. no), history of cardiovascular disease (yes vs. no), history of diabetes (yes vs. no), albumin $(3.1-3.5,3.6-4.0,>4.0$ vs. $\leq 3.0 \mathrm{~g} / \mathrm{dL})$, creatinine (continuous), phosphorous $(4.1-5.0,5.1-6.0,>6.0 \mathrm{vs}$. $\leq 4.0 \mathrm{mg} / \mathrm{dL})$, hemoglobin $(10.0-$ $11.9, \geq 12.0 \mathrm{vs} .<10.0 \mathrm{~g} / \mathrm{dL}$ ), urea reduction ratio (continuous), pre-HD systolic blood pressure $(131-150,151-170,>170 \mathrm{vs} . \unlhd 30 \mathrm{mmHg}), \mathrm{missed}$ sessions ( $\geq 3$ vs. $<3$ ). Subgroups of interest were excluded from the adjustments listed above. Significance of interaction terms was determined using Wald chi-square (type 3 ) tests.

Abbreviations: $\mathrm{CI}$, confidence interval; UF=ultrafiltration, $\mathrm{HD}=$ hemodialysis, HR, hazard ratio; IDWG=interdialytic weight gain, 